\title{
SUJETOS RURALES QUE POR PRIMERA GENERACIÓN ACCEDEN A LA UNIVERSIDAD Y SU DINÁMICA DE MOVILIDAD SOCIAL EN LA REGIÓN DEL MAULE
}

\section{Interés investigativo}

Los procesos modernizadores que han afectado al país en los últimos 30 años generan profundas transformaciones en el mundo rural, las que se expresan en su estructura productiva, demográfica, de tenencia de la tierra, como también en la forma en que los habitantes del campo perciben su mundo y se perciben a sí mismos (Canales, 2005).

La década de los 90 marca el quiebre con la concepción clásica de lo rural asociado a lo tradicional o atrasado. La radicalización de los procesos de modernización en las explotaciones agrícolas, el aumento de calidad y cantidad de servicios, el desarrollo de infraestructura -conectividad vial y comunicacional-, el surgimiento de nuevas actividades agrarias y terciarias, los mayores niveles educacionales, entre otros, producen nuevas condiciones que en el ámbito de las ciencias sociales se conceptualizan como "nueva ruralidad"2.

En este contexto de complejidad, lo rural no se puede pensar sólo en función del trabajo agropecuario, sino de las demás actividades que son desarrolladas por la población, con una perspectiva de interdependencia con lo urbano, lo que se refleja en un sistema de estratificación social que se transforma. Estos cambios generan una nueva estructura de oportunidades que, siguiendo las ideas de Atria (2004), se encuentra determinada por factores como la inserción en la estructura ocupacional laboral y el acceso a la educación.

2 Término utilizado por Edelmira Pérez, que alude a las transformaciones que vive el mundo rural. En un escenario de complejidad, se redefine el ser rural en relación con lo que tradicionalmente se conceptualizaba como atrasado y vinculado exclusivamente a labores agrarias. 
Las mejoras en los niveles educacionales en la población rural generan diferencias intergeneracionales de escolaridad más pronunciada que en la urbana. Los jóvenes rurales del país tienen en promedio 6,9 años más de escolaridad que sus abuelos y 3,8 más que sus padres. Acompañan a estos cambios la expansión de la educación universitaria, que favorece el ingreso de poblaciones históricamente excluidas del circuito (el incremento sostenido en los últimos 16 años de la cobertura neta de asistencia en el ámbito nacional se duplica a un $27,6 \%$ en 2006, para la población entre 18 y 24 años) (Casen, 2006).

De este modo el sistema universitario en el país se ha transformado desde uno de elite en manos del Estado a uno de masas y privado, caracterizado por ser altamente diferenciado (Brunner, 2006), con un mercado jerárquico, segmentado y reputacional.

En la Región del Maule la expansión de la oferta universitaria ha permitido que primeras generaciones del mundo rural -hijos de campesinos, pescadores, temporeros, artesanos, prestadores de servicios- ingresen a universidades regionales, tanto públicas como privadas. En este contexto, surge la inquietud por conocer hasta qué punto las nuevas oportunidades educacionales afectan la movilidad social de estos individuos, si se considera que, tradicionalmente, el logro educativo es visto como el principal mecanismo para acceder a mejores posiciones en la estructura social.

Las investigaciones en movilidad social han enfatizado el enfoque cuantitativo al abordar su objeto de estudio. Un especializado manejo de datos estadísticos entrega mediciones que permiten observar, a través de indicadores, las condiciones de vida de los individuos a lo largo del tiempo; sin embargo, presenta ciertos inconvenientes para referirse a cómo el individuo percibe su movilidad social, si logró las expectativas que se había formado, cuáles fueron los mecanismos que utilizó, en qué condiciones llegó.

Como una forma de contribuir a iluminar el conocimiento, se utilizó la perspectiva cualitativa, con el fin de develar aquellos aspectos que marcan las oportunidades que el sujeto tiene a lo largo de sus 
itinerarios de vida, así como el significado que otorga a la educación universitaria en sus procesos de movilidad social. El enfoque utilizado fue la teoría fundamentada (Glaser y Strauss, 1967). A través de un proceso inductivo en el análisis de los casos, se configuraron las hipótesis de trabajo que, a partir del método de la comparación constante, se sometieron a validación.

Las hipótesis que guiaron el proceso de búsqueda apuntaron básicamente a develar:

i) Si la educación universitaria es un mecanismo efectivo de movilidad social en aquellos sujetos con familias de origen pobre y de clase media baja, quienes perciben no sólo mejorías en sus condiciones de vida, sino un cambio en la clase social a la que pertenecen.

ii) Los individuos que acceden a universidad privada de baja reputación, siguiendo las categorías de Brunner (2006), estarían en desventaja a la hora de acceder a puestos de trabajo, generando un proceso clasista de selección al interior del sistema educacional.

iii) Las familias de clase media instalarían como proyecto de vida -cultura de la educación- el ingreso a la educación universitaria como una forma de asegurar la reproducción de la posición social de origen y mejorar el nivel de vida de sus hijos.

iv) La profesionalización de estas nuevas generaciones traería implícitos procesos de desruralización, ya que no existiría una oferta laboral adecuada en sus lugares de origen, obligando a los sujetos a migrar. De este modo, los procesos de movilidad social se vincularían con nuevos territorios fuera de la región del Maule.

El artículo se estructura en cuatro ejes temáticos. El primero, antecedentes sobre movilidad social, introduce las aproximaciones teóricos conceptuales en que se basa el estudio, incluyendo la discusión nacional en esta materia. El segundo da cuenta de la metodología empleada, resaltando los procedimientos e instrumentos utilizados para recabar, en forma rigurosa y válida, la información. El tercero está dedicado a dar cuenta de los principales hallazgos de investigación a partir del análisis de 32 entrevistas biográficas. 
Finalmente, se incluyen la discusión y conclusiones que responden a los objetivos e hipótesis de investigación para contribuir al debate sobre el problema de la educación como mecanismo de movilidad social, en una creciente expansión del sistema universitario.

\section{Antecedentes sobre movilidad social}

En la actualidad, el análisis de la movilidad se ha centrado en el factor educacional. Como señalan León y Martínez (2001), la creciente valoración que la sociedad otorga al acervo educacional -lo que supone en términos de posibilidades efectivas de ascenso en la escala ocupacional y de ingresos- podría determinar en gran medida el ascenso o descenso de los individuos en la escala social.

Diversas teorías avalan que, en la sociedad moderna, la educación jugaría un importante papel en el acceso a nuevas posiciones en la estructura social. El supuesto es que, a mayores niveles de capacitación, las personas pueden ocupar mejores puestos de trabajo y aumentar sus ingresos económicos. De esta manera, los factores adscriptivos no son relevantes para ocupar un empleo, enfatizando los criterios de selección y promoción basados en el desempeño individual. En consecuencia, la "meritocracia" responsabiliza al individuo por la posición social que logre ocupar: las oportunidades están a disposición de toda la población, depende de las capacidades y habilidades individuales.

En oposición a esta visión, Atria (2004) señala que “... diversas investigaciones indican que la expansión del sistema educacional en sí misma no necesariamente reduce las desigualdades sociales de clase, en cuanto a la oportunidad del logro educativo. Las personas que provienen de hogares con un mayor capital cultural alcanzan mayores y mejores logros educativos, de modo que las desigualdades son difíciles de eliminar y tienen efectos en la reproducción de las desigualdades intrageneracional e intergeneracional".

En esta perspectiva, la teoría de la reproducción social (Bourdieu y Passeron, 1995) señala que el sistema educativo reproduce 
las diferencias de origen social. El factor decisivo no es la competencia técnica del candidato para el empleo, sino su identificación y manejo de culturemas (habitus).

Para Bourdieu, las clases sociales resultan de la posición ocupada en el espacio social (campo). Según los capitales que se posean -económicos, sociales, culturales y simbólicos- será el habitus, gustos, prácticas y estilos de vida. La posición social está fundamentalmente marcada por la trayectoria de clase de la familia de origen y no por la vía de los méritos individuales.

En la corriente de la reproducción (Rodríguez, 1998), se pueden distinguir dos grandes líneas: una que aborda los aspectos culturales de la reproducción ideológica-línea subjetiva-y otra que se concentra en la formación de estructuras de segmentación y selección dentro y fuera de la escuela, que se expresa en procesos discriminatorios de la distribución y acceso de bienes valorados socialmente. En los diferentes segmentos y clases de empleos profesionales está presente una serie de elementos subjetivos, como el prestigio que confiere la pertenencia a cierta profesión u ocupación laboral y que alimenta las expectativas de llegar a cierto estatus, nivel económico, roce social y poder. Pero también está la presencia de elementos objetivos, como el real desempeño de la profesión y las remuneraciones que se obtienen. Ambas condiciones -objetivas y subjetivas- definen las expectativas y la valoración que tienen los individuos y sus familias respecto del ingreso a la universidad y la elección de la carrera.

La devaluación de los títulos profesionales, como señala Boudon (1983) demuestra los "efectos perversos" que se generan con la expansión de la educación universitaria. A través de diversos estudios empíricos, éste determina que no existe relación de correspondencias entre ingreso, posición ocupacional y acceso a bienes culturales. Estamos frente a una población con mayor capacitación y con un mercado de trabajo incapaz de absorber la mano de obra; esto obliga a los individuos a perfeccionarse para acceder a puestos de trabajo que muchas veces requieren menos conocimientos. Los individuos reconocen la disminución de su inversión al acceder a la educación superior; sin embargo, pese a este elemento negativo, están conscientes que de no invertir los resultados serían peores. 
Bourdieu y Passeron (1995) introducen la idea de una doble lógica en el juego de la educación. Por un lado están las necesidades de mano de obra calificada -lógica del sistema-; por otro, las exigencias de las familias en materia de movilidad social -lógica de los actoresy ambas demandas están conectadas pero desajustadas entre los requerimientos del mercado y las expectativas sociales de movilidad, lo que provoca como tendencia la devaluación de los títulos y grados académicos, situación que se expresa en que determinados títulos profesionales cuentan con mayor posibilidad de inserción laboral y otros enfrentan la saturación de los mercados.

\section{La discusión nacional sobre movilidad social}

En el análisis de la estructura social chilena, León y Martínez (2001) construyen una matriz de categorías sociales ${ }^{3}$, diferenciando capas o generaciones históricas que han ido constituyendo las clases. Los hallazgos más relevantes muestran que el nuevo modelo de acumulación neoliberal produce importantes transformaciones en la estructura ocupacional del país. En relación con la educación, estos autores manifiestan que el ingreso ha sido débilmente compensado, a pesar del acortamiento en las distancias educativas producto de la expansión del sistema educacional y la mayor escolaridad de la población. Al interior de las nuevas generaciones, las distancias interclasistas continúan siendo muy pronunciadas y permanecen como barreras difícilmente superables para la movilidad social.

Un segundo estudio bajo este mismo enfoque es el realizado por Torche y Wormald (2004), en el cual los resultados coinciden en varios aspectos. Se constata un importante proceso de transformación socioeconómica en las últimas décadas, que ha repercutido en las oportunidades de movilidad social.

3 Basadas en el modelo propuesto por R. Erickson y J. Goldthorpe, toman la dimensión del control que ejercen determinados grupos sociales sobre los recursos escasos y valorados socialmente, tales como: la propiedad de los medios de producción, el control y la autoridad sobre el trabajo de otros, así como también el control sobre las destrezas ocupacionales escasas (educación y calificación) y las posibilidades que tienen estos grupos de acceder a las oportunidades sociales (educación, trabajo, riqueza), las que eventualmente les permiten redefinir sus patrones de inserción social. 
Con relación a la educación, el estudio concluye que el acceso a la estructura de oportunidades educacionales ha sido aprovechado por los diversos grupos sociales de manera diferencial. La expansión de la oferta educativa y su valoración como mecanismo de movilidad social ha significado un alza en los niveles de escolaridad; sin embargo, el retorno económico para las clases medias bajas es desfavorable.

Desde un enfoque cualitativo para la comprensión de la dinámica de la movilidad social, Márquez (2001) indaga en las trayectorias laborales de hombres y mujeres pobres habitantes de campamentos de la ciudad de Santiago de Chile. Las conclusiones son que la mayor o menor movilidad social de los sujetos se basa en la compleja y estrecha articulación de tres ámbitos: i) la estructura de oportunidades en la que desenvuelven sus vidas, con la sociabilidad como un recurso central para el acceso a un sistema o red de protección social; ii) la cultura como matriz básica de orientaciones a la acción; y iii) la capacidad del sujeto de construir y desarrollar procesos de individualización que le permitan transitar y valerse de esta estructura de oportunidades y soportes de la cultura.

Siguiendo este enfoque, Méndez (2002) realiza un estudio que busca el significado asociado a la movilidad social en 12 familias de la comuna de La Florida en la Región Metropolitana. Concluye que, aun cuando las familias han vivenciado procesos históricos y sociales similares, las nociones, significados y experiencias de movilidad tienden a ser diversos. La movilidad coincide con el valor de la educación, el trabajo y la casa propia. Los resultados muestran que los sectores bajos presentan mayores trayectorias ascendentes en una lógica de integración que se manifiesta como aceptación. Para el caso de las clases medias, en cambio, la movilidad ascendente aparece ligada a lógicas de competencia y de subjetivación que se manifiestan como oportunismo.

\section{Metodología}

El diseño de investigación fue de casos múltiples (Rodríguez, 1996), como un procedimiento abierto y flexible que entrega una descripción y un análisis que permiten incrementar el alcance de cada caso, al 
tiempo de asegurar cierta lógica de replicación de los hallazgos. Cualquier intento de generalización se fundamenta en el examen de los datos obtenidos en el contexto social de los sujetos investigados.

El instrumento para recabar la información fue la entrevista en profundidad con enfoque biográfico. A través del relato, se buscó construir la dinámica social del tiempo que les tocó vivir -pasado, presente- para dar cuenta de los procesos histórico-sociales que han afectado su vida y la del mundo.

Para obtener los casos se utilizó el "muestreo teórico", especialmente recomendado para problemas investigativos en los que se buscan perspectivas particulares o interpretación integrales. Los criterios de selección de la muestra consideraron:

1. Titulados de la cohorte 2003-2004 de origen rural ${ }^{4}$ de la región del Maule. La elección de la cohorte se justifica a partir de requerimientos específicos solicitados por la contraparte del estudio (Emmanuelle Barozet), quien señala la importancia de establecer un tiempo de cuatro a cinco años, desde que el sujeto se incorpora idealmente al mundo laboral, para registrar su movilidad social.

2. Primera generación en la familia que accede la educación universitaria. Se incluyen familiares con educación no universitaria (profesores normalistas, técnicos, entre otros).

3. Egresados de instituciones público-privadas de la región del Maule que para esta cohorte contaban con titulados, y consentimiento institucional para la entrega del banco de datos.

De acuerdo con estos criterios de inclusión y selección, tres de las cuatro universidades regionales fueron incorporadas al estudio. La universidad faltante no accedió a entregar los datos de sus alumnos titulados.

4 Se definió como rural aquellas localidades en que su principal actividad productiva se concentra en labores de pesca-agricultura-forestal, o asociadas a este rubro, como turismo rural, venta de insumos agrícolas/forestal/pesca, prestaciones de servicios al agro/forestal/ pesca, etc.; quedaron excluidas las comunas de Talca, Curicó, Linares y Constitución, debido a que su actividad productiva se concentra en el sector servicios. 
Los entrevistados que participan de la investigación corresponden a la primera oleada rural -cohorte 1997-1998- que se incorpora al sistema universitario en el contexto de los procesos de expansión en la región. En este sentido, resulta interesante saber qué pasó con esta primera generación de profesionales. Los hallazgos permiten conocer la percepción que tienen los sujetos acerca de las nuevas oportunidades educativas en relación con el mercado laboral, ingresos, redes sociales, por ejemplo, así como acerca de los cambios y continuidades en su posición social respecto de sus familias de origen. Esta información ayuda a estimular el debate sobre la efectividad de la educación como mecanismo de movilidad social, con el fin de considerar los ajustes institucionales que permitan mejorar los procesos de profesionalización.

Se realizaron 32 entrevistas biográficas, correspondientes a 18 mujeres y 14 hombres; 11 entrevistados de la Universidad de Talca, 13 de la Universidad Católica del Maule y 8 de la Universidad Autónoma de Chile 5 .

El criterio de validez de la información operó bajo el principio de redundancia (o saturación), entendida como el agotamiento de la información o efectos de sentido no conocidos previamente. "Como esquemas de significación, la información es finita. Por ello la repetición no agrega información. Así, la representatividad del conocimiento producido está dada en la forma del objeto reconstruido. Lo que circula como lo social es precisamente lo formado, compartido, los esquemas o códigos o lenguas comunes" (Canales, 2006).

\section{Principales hallazgos}

Los principales resultados se desglosan en cinco partes, que tienen como propósito develar las interpretaciones que los entrevistados hacen respecto de su proceso de movilidad social a partir del acceso a la educación universitaria. La primera sección muestra el contexto familiar y social del cual provienen los sujetos y cómo, a través de

5 Los alumnos titulados de la Universidad Autónoma de Chile que ingresaron entre 1997 y 1998 lo hicieron al Instituto Profesional Valle Central, que en la década del 2000 se transformó en universidad privada, en el contexto de la expansión del sistema universitario. 
estas experiencias, resultan -para sí mismos- caracterizados. La segunda indaga en la participación de la estructura de oportunidades educativas. Una tercera sección describe la experiencia laboral y los factores que estarían afectando su desarrollo. La cuarta explora en los elementos que el sujeto significa como explicativos de la movilidad social y, por último, en la quinta sección se expone la visión del mundo rural y las proyecciones que se visualizan en la región del Maule.

\section{Contexto familiar y social del cual provienen los sujetos}

A través del análisis de los datos, se construyó una tipología que permite describir la posición social que asignan los sujetos a su familia de origen a partir de logros económicos y prestigio social alcanzado.

a) Familias de origen pobre

Se constituyen en la década del 70. Corresponden a seis casos que habitan principalmente en el secano costero o en localidades aisladas con actividades agrícolas de subsistencia. Viven en las comunas de Vichuquén, Licantén o en localidades como Aquelarre, Iloca, Cerro los Castillos y Bobadilla.

Tres casos recuerdan que sus abuelos eran campesinos dedicados a cultivos tradicionales en mediería y en el área de extracción minera en otros territorios.

Con relación a sus familias de origen, las identifican como clase baja -pobres- por falta de acceso a bienes y servicios, con necesidades básicas insatisfechas. Sus viviendas son mayoritariamente de adobe o madera en regular estado, con cobertura de servicios básicos, exceptuando alcantarillado.

El trabajo de sus padres es de carácter temporal y de subsistencia. Se desempeñan en labores agrícolas (temporero, mediería) o de servicio con baja calificación (empleadas domésticas, lavanderas, jardineros).

El nivel educacional de los padres es bajo, con estudios básicos incompletos y, en algunos casos, analfabetos. Para los entrevistados, 
la falta de capital cultural y económico de los padres determina que la educación no represente un valor central, no invierten tiempo ni recursos para ubicar a sus hijos en el sistema educativo ni tampoco tienen la preparación para ayudarlos y motivarlos en la tarea.

Las familias están constituidas por madres solteras jefas de hogar, madres solteras con pareja, madres separadas, viudas y una pareja unida a través del matrimonio. Son numerosas, con más de cinco hijos, los que desde pequeños son incorporados al mundo laboral, con una infancia recargada de responsabilidades. Como las familias están centradas en la subsistencia, no se visualizan proyectos familiares: se vive el día a día.

Perciben a sus padres sin reconocimiento social por falta de recursos económicos, desempeño en trabajos precarios y, en algunos casos, vicios asociados al padre. Los contactos sociales son de tipo familiar, con escasa información y redes donde acudir.

Los hechos que marcan a los entrevistados se relacionan con la precariedad económica, experiencias de abandono, abuso sexual y trabajo infantil.

b) Familias de origen de clase media baja Se constituyen en la década del 70. Corresponden a nueve casos que habitan en localidades con mayor accesibilidad del valle central y con influencia de procesos modernizadores: San Javier, San Clemente, Molina, Parral y Villa Alegre.

Los abuelos pertenecen a familias pobres dedicadas al trabajo agrícola en mediería, algunos son propietarios de pequeñas parcelas, administradores de propiedades agrícolas y prestadoras de servicios a la ruralidad.

Identifican a sus familias de origen como clase media baja, por la falta de acceso a bienes y servicios, con espacios limitados de consumo, pero con necesidades básicas satisfechas. El acceso a la vivienda es a través de tomas de terrenos con posterior regularización o por subsidios sociales. Algunas familias viven de allegadas principalmente en casas de abuelos. 
Los padres tienen estabilidad laboral relativa, desempeñan prestaciones de servicios agrícolas o comercio, fletes de productos agrícolas, operarios de maquinaria agrícola, vendedores, modistas y mecánicos.

Las familias están constituidas por parejas unidas en matrimonio, madres separadas jefas de hogar, con un número menor a cinco hijos.

La escolaridad de los padres transita entre educación básica incompleta y media incompleta. Al menos uno de los progenitores instala el proyecto educativo para los hijos, invirtiendo tiempo y recursos para su ejecución. El objetivo es la adquisición de competencias que permitan mejores ocupaciones e ingresos; para el caso de las mujeres se busca la independencia económica.

Respecto de los contactos sociales, presentan vínculos con familia extendida que les permiten acceder a presupuestos familiares, para formar economías domésticas comunes y con redes asistenciales, municipios o iglesia católica. Son familias reconocidas socialmente en las localidades por el esfuerzo que invierten en sacar adelante a sus hijos.

La infancia está marcada por lazos familiares fuertes con recuerdos de acompañamiento y contención. Reconocen que sus padres son personas de esfuerzo, centradas en la subsistencia del núcleo familiar, que buscan satisfacer las necesidades básicas y educacionales de los hijos.

c) Familias de origen de clase media

Se constituyen en la década del 70, corresponden a diecisiete casos que habitan en localidades rurales, con baja y alta accesibilidad: San Javier, San Clemente, Molina, Villa Alegre, Hualañé, Pencahue, Sagrada Familia y Rauco.

Los abuelos son campesinos propietarios de terrenos agrícolas dedicados a cultivos tradicionales o producción de vinos, otros son administradores de fundos y prestadores de servicios (panaderos, profesores normalistas). 
Sus padres presentan mejoras sustantivas en relación con sus abuelos, se identifican como familias de clase media que comenzaron con escasos bienes y que debido al esfuerzo familiar lograron ascender. Tienen sus necesidades básicas satisfechas con acceso al consumo, casa propia y, en algunos casos, vehículo.

Las ocupaciones de los padres son heterogéneas: propietarios agrícolas, en su mayoría por herencia familiar, que se dedican a la producción tradicional de viñas, hortalizas y huertos frutales; comerciantes independientes, con locales de abarrotes, carnicerías, botillerías; otros que comenzaron como empleados no calificados y terminaron con profesiones técnicas (paramédico y secretaria en un colegio). Las mujeres profesionales con formación docente en escuelas normales ejercen su profesión en sectores rurales y han establecido relaciones de pareja con sujetos dedicados al agro y servicio a la ruralidad.

Los padres presentan un nivel educacional que va desde la enseñanza básica y media incompleta a la educación media completa en escuelas agrícolas, técnico profesionales o normales. En ambos padres existe una alta valoración por la educación, la que es concebida como proyecto de familia, por lo que privilegian las escuelas urbanas.

Son familias constituidas principalmente por parejas unidas en matrimonio, con menos de cuatro hijos. La infancia es considerada normal, con fuertes lazos familiares. Perciben a sus padres centrados en el trabajo, generando condiciones económicas que permitan el desarrollo educacional y personal de los hijos.

Consideran que sus familias son reconocidas en la comunidad (prestigio social) debido a sus logros económicos, a la participación política y en organizaciones comunitarias. Respecto de los contactos sociales, presentan vínculos con familias extendidas, se relacionan con profesionales, empresarios del área agrícola, organizaciones sociales, políticos y profesores. 


\section{Análisis de la estructura de oportunidades educativas}

Los resultados se organizan de acuerdo con i) participación en el sistema escolar, ii) cómo se configura la idea de ingresar a la universidad, iii) expectativas de la universidad, iv) elección de carrera, v) proceso de formación.

\section{i) Participación en el sistema escolar}

Las oportunidades educativas están marcadas por diversos factores. Uno de ellos es el territorio en el cual habitan las familias: aquellos con un modelo productivo agroindustrial tienen mayores posibilidades de acceder a centros educativos de calidad que los del secano costero. Un segundo factor es la presencia de un proyecto educativo en la familia, pues los moviliza para buscar en la ciudad una mejor educación, en algunos casos influenciados por profesores y autoridades de la localidad.

Finalmente, algunas familias a pesar de tener un proyecto educativo para sus hijos, no pueden acceder a centros de calidad, debido a sus precarias condiciones económicas, teniendo que participar de la oferta educativa local.

Los centros a los que acuden a estudiar en su etapa escolar son municipales. Sólo tres casos asisten a establecimientos particulares subvencionados.

La siguiente tipificación muestra las características de los establecimientos:

- Rurales unidocente y multigrados ${ }^{6}$, se ubican en zonas del secano costero, la formación recibida (adquisición de contenidos mínimos obligatorios) es considerada deficiente. Las expectativas educacionales de los profesores y de las familias son bajas, no enfatizan la continuidad de estudios.

- Municipales y subvencionados particulares rururbanos ${ }^{7}$, a los

6 Unidocentes: establecimientos municipales, hasta sexto básico, que cuentan con un docente. Multigrados: establecimientos municipales, con enseñanza básica, con docentes que atienden varios cursos.

7 Rururbanos: la idea pretende caracterizar a un continuo que toma distancia de las lecturas polares, que separan lo rural/urbano. Se parte del supuesto que desde la década de los 80 ambos territorios se penetran y articulan, modificando la dinámica y la lógica de los espacios, sin que por ello se anulen rasgos propios. 
que asisten jóvenes que provienen de centros unidocentes y multigrados que buscan continuar sus estudios en localidades cercanas, debido a que sus familias no tienen los medios económicos para costear estudios en la ciudad. Los que habitan en estas localidades, por factores económicos y/o para no exponer a sus hijos a los riesgos de las grandes ciudades, continúan sus estudios en las zonas de origen.

La formación es considerada deficiente por las bajas expectativas de los profesores, padres y alumnos. Reconocen que los centros de formación, en general, no tienen un discurso ni una práctica institucional que oriente hacia la educación universitaria. La baja calidad de la formación se expresa en un déficit en el manejo de contenidos, falta de hábitos de estudio, rigor y disciplina de trabajo.

- Urbanos municipales y subvencionados particulares, a los que asisten jóvenes provenientes de familias que tienen un proyecto educativo, medios económicos y contactos sociales. Tres entrevistadas ingresan desde su infancia a establecimientos urbanos. Dos señalan que las razones de esta decisión es la convicción de los padres de encontrar en la ciudad una enseñanza pública de calidad. Sólo una entrevistada accede desde la infancia a un colegio particular subvencionado gracias a los contactos sociales de los padres.

Quienes ingresan a establecimientos científico-humanistas muestran un claro interés por acceder al sistema universitario; los que optan por liceos técnico-profesionales aspiran a una profesión, asegurando así una credencial para contrarrestar la inestabilidad de la economía doméstica.

La formación de estos alumnos está marcada por sentimientos de integración y exclusión social. Para aquellos que deben entrar en un régimen de internación, es la valoración del esfuerzo familiar lo que los mantiene en el sistema, pues la pérdida de contacto con sus familias y el tiempo de adaptación a nuevos hábitos de vida les hacen pensar en la deserción. 
La incorporación al espacio urbano ("la ciudad") se vive con inseguridad. Deben aprender a manejar códigos y patrones de conducta, iniciando nuevos procesos de socialización. Algunos encuentran grupos de pares con características similares, facilitando su integración. Para otros, la experiencia es de exclusión y la explican a partir de ciertos rasgos personales propios de la ruralidad que afloran al enfrentarse a experiencias nuevas: timidez, sumisión, confianza, espíritu sano. Otro de los factores que afecta el proceso de integración es su bajo rendimiento académico, atribuido a la precaria preparación escolar recibida en sus localidades de origen.

ii) Cómo se configura la idea de ingresar a la universidad El motivo para ingresar al sistema universitario se explica por varias razones. La complejidad de las experiencias genera expectativas diferentes en cada familia, evidenciando un desarrollo desigual de la cultura de la educación, entendida como las aspiraciones y valoraciones que se tienen respecto del acceso a la educación.

1) Como proyecto familiar: la educación se incorpora tempranamente como una aspiración y necesidad, para la cual se diseñan estrategias y acciones que permitan el logro del objetivo. El ingreso a la universidad es un mandato familiar: es la única alternativa que permite mejor ocupación, remuneración e independencia económica, en el caso de las mujeres.

Las familias, como no pueden heredar a sus descendientes capital económico, orientan sus energías al desarrollo del capital cultural de sus hijos, para que con sus títulos produzcan su propio capital económico y social que mejore su posición social o la mantenga.

La alta valoración de la educación como mecanismo de movilidad social se atribuye a las familias de clase media. Sólo cuatro familias de clase media baja incorporan tempranamente el proyecto educativo, lo que pudiera explicarse por el trabajo de los padres, quienes, al ser prestadores de servicio en el mundo rural, se contactan con grupos sociales prestigiosos que podrían estar influyendo en sus decisiones. 
2) Modelos externos: presencia de profesionales que influyen en el ingreso a la universidad. Las experiencias en las que el sujeto percibe la práctica docente como modelo para imitar en la adultez o un profesor que valora sus capacidades académicas incentivan su ingreso a la universidad.

También se constató que el sujeto resulta marcado por profesionales del área agrícola y salud. Para un joven con bajo capital cultural y social, el contacto con otras profesiones posibilita un rediseño de las expectativas de vida. Los entrevistados que están motivados por modelos externos pertenecen principalmente a familias de origen de clase media baja y pobres.

3) Pobreza familiar: es una respuesta a las experiencias de vulnerabilidad social en la infancia; resistencia a repetir la historia de pobreza familiar. El contacto con el sistema escolar refuerza la idea de la educación como mecanismo para superarla. Algunos casos son marcados por experiencias laborales con bajas remuneración y malos tratos, incentivando su decisión por ingresar a la universidad.

iii) Expectativas que el sujeto tiene de la universidad

Por expectativas de la universidad se entenderán aspiraciones y metas que el sujeto traza con la finalidad de alcanzar posiciones diferenciadas en la estructura ocupacional y de ingresos. Los sujetos perciben que, a través de la obtención de credenciales, tendrán mayores oportunidades para acceder a mejores ocupaciones, ingresos y niveles de vida más altos que los de su familia de origen. Las expectativas, en general, se orientan al acceso de bienes como "el auto" y "la casa propia". Se espera que la educación universitaria asegure el trabajo y la estabilidad laboral para tener un buen pasar y tranquilidad económica. Sólo las mujeres señalan como aspiración la búsqueda de independencia económica, pues les permitirá tomar sus propias decisiones en un entorno que califican de "machista".

iv) La elección de la carrera

Qué estudiar depende de la posición que ocupe el sujeto en los espacios sociales y del volumen de capital económico, social y cultural 
de las familias de origen. Un grupo importante de entrevistados no tiene un claro interés por una carrera específica, sus habilidades los inclinan a ciertas áreas del conocimiento $u$ obedecen a intuiciones, pues carecen de información para tomar decisiones, lo que podría explicarse por el escaso capital cultural y social de las familias, en las que los jóvenes carecen de referentes con estudios superiores que orienten su elección.

Por otra parte, el puntaje obtenido en la Prueba de Aptitud Académica (PAA) restringe las opciones. Para algunos, el resultado bajo lo esperado implica ingresar a una carrera de segunda opción que se relacione con el área del conocimiento más competente. Para otros, ingresar a la oferta que existe en el mercado de la educación superior privada, que para el periodo en estudio es restringida.

Los que declaran elegir la carrera por vocación, explican que participar en organizaciones religiosas y los modelos docentes de la infancia influyen en su decisión. A través de sus profesiones, señalan que buscan apoyar a sus comunidades de origen. Las carreras asociadas a la vocación son Trabajo Social, Enfermería y Pedagogía General Básica.

Finalmente, la falta de medios económicos y de información restringe las posibilidades de optar a carreras fuera de la región.

v) El proceso de formación

Para la mayoría de los casos el primer año fue una experiencia compleja. Las razones fueron la débil formación escolar que se expresa en el insuficiente manejo de contenidos, falta de hábitos de estudio y disciplina de trabajo. Esto redundó en que el desempeño académico no guardaba relación con sus experiencias escolares, en las cuales fueron generalmente los mejores alumnos de la clase.

Algunos casos señalan que la falta de vocación asociada al desconocimiento de los contenidos de la carrera afectó los rendimientos, surgiendo el deseo de desertar del sistema, pero continuaron porque valoraron al esfuerzo familiar y temieron decepcionar a sus padres. Para el caso de los jóvenes que no tenían 
un proyecto educativo familiar, las razones se atribuyeron al esfuerzo personal invertido.

Finalmente, frente a los bajos rendimientos, la mayoría coincide que en tercer año lograron nivelarse gracias a las diversas estrategias utilizadas: aumentaron las horas de estudio, asistieron a ayudantías, formaron grupos de estudio o intercambiaron favores con conocidos en otras carreras.

La formación es evaluada positivamente, aun cuando existen algunos reparos:

a) Docencia: los resultados se orientan principalmente al ámbito de las relaciones interpersonales. Los casos que estudian en las áreas de salud e ingeniería se refieren al trato impersonal y clasista de los académicos, con una mala disposición a enseñar. Una visión contrapuesta es la de carreras de corte humanista ${ }^{8}$, en las cuales se señala que las relaciones entre docentes y alumnos son próximas, lo que es altamente valorado.

b) Currículo: se considera con una fuerte orientación teórica y un escaso vínculo con la realidad. Critican el poco tiempo dedicado a las prácticas profesionales, considerando que es el espacio de aprendizaje por excelencia, en el cual se generan contactos, redes y habilidades sociales relevantes a la hora de insertarse laboralmente.

Para la mayoría de los entrevistados, la formación universitaria no contempla el desarrollo del capital social individual, entendido como la habilidad social que permite relacionarse positivamente, ser asertivo, emprendedor, ejercer liderazgo. Dato relevante por el perfil de los entrevistados, que se reconocen carentes de redes, contacto sociales y de los habitus que exige el mercado laboral.

\section{El mundo del trabajo}

Si consideramos que los entrevistados esperan de la universidad acceso a mayores ingresos y mejores posiciones en la estructura ocupacional,

8 Las carreras humanistas sólo se imparten en Universidad Autónoma de Chile y Universidad Católica del Maule. 
los resultados no son similares para todos los casos. Existen diversos factores, como la oferta de titulados que supera la demanda, la calidad de los empleos, la politización de las áreas de trabajo, la calidad de los contactos sociales y el capital social individual ${ }^{9}$, que afectan la vida laboral.

Para conocer cómo inciden estos factores en la vida laboral de los entrevistados, los resultados se mostrarán por áreas de especialización.

1. Economía: componen esta área tres ingenieros comerciales de universidad estatal y dos contadores auditores de universidad estatal y universidad privada respectivamente. Para ambas profesiones la primera inserción laboral fue compleja por la excesiva oferta de titulados en la región y la limitada red de contactos sociales, lo que provocó el traslado de dos ingenieros comerciales a la región del Libertador Bernardo O’Higgins y a la Metropolitana en busca de mejores oportunidades.

El tiempo que tardan en encontrar trabajo es de uno a dos años. Destaca el caso de una ingeniera comercial, titulada en 2003, que no logra insertarse laboralmente. Como el periodo de búsqueda es prolongado, algunos entrevistados realizan otras labores vinculadas con servicios (cajeros de supermercados, clases de capacitación en OTEC, transporte de productos agrícolas, entre otros).

Los mecanismos para acceder al trabajo fueron por contactos débiles (Granovetter, 1973) ${ }^{10}$, compañeros y profesores de la universidad o contactos de los padres con antiguos empleadores.

La movilidad ocupacional es baja. Sólo tres casos estarían cursando su segunda ocupación. Actualmente tres entrevistados

9 Son aquellos aspectos personales-sociales, como la capacidad de relacionarse positivamente, trabajar en equipo, ser asertivo, empático, ejercer liderazgo y mostrar una actitud emprendedora y responsable.

10 Granovetter (1973) clasifica los contactos o lazos en fuertes y débiles. Los primeros generan un tipo de información compartida que establece círculos cohesivos; los segundos proveen una información escasa dentro de un núcleo de relaciones cercanas, lo cual podría influir positivamente al individuo en el acceso a oportunidades y recursos. 
trabajan de forma dependiente, uno mixto y uno independiente. Los ingresos (miles de pesos) para los contadores auditores están entre 251-451; los ingenieros comerciales entre 451-651; 0-251 un caso que no ha encontrado trabajo en esta profesión.

2. Ciencias Agrarias: cinco ingenieros agrónomos. Cuatro de universidad estatal y uno de universidad privada con apoyo estatal. La inserción laboral para este grupo es rápida, con seis meses como tiempo máximo. Los mecanismos utilizados son el intercambio de favores y en un caso mérito. En cuanto a la movilidad ocupacional, dos casos señalan que es alta. Las razones son la estacionalidad del trabajo agrícola, empleos en proyectos de corto plazo y una oferta de profesionales que ha ido en aumento.

Actualmente, cinco son trabajadores dependientes: tres en empresa privada y dos en el área pública. Las remuneraciones (miles de pesos) son heterogéneas; dos casos, especialistas en enología, reciben ingresos 1.000-1.500; dos casos, entre 451-650 y un caso entre 251-451.

3. Ciencias Sociales: componen esta área seis trabajadores sociales. Cuatro son de universidad privada y dos de universidad privada con apoyo estatal. La inserción laboral depende de contactos sociales y políticos. El tiempo máximo para encontrar trabajo es un año. En cuanto a la movilidad ocupacional, en los seis casos es alta. El mercado de trabajo funciona por proyectos o programas a corto plazo y se observa un aumento en la oferta de profesionales.

Se desempeñan directamente o indirectamente (empresas subcontratistas) en programas del Estado. Cuatro casos reconocen trabajar en más de un empleo y distribuyen sus jornadas por proyectos. Tienen una mala percepción del Estado como empleador. Los programas sociales son por media jornada y la situación contractual es a honorarios, sin previsión social.

Advierten que el trabajo es inestable por la excesiva politización de los municipios: dependen del alcalde de turno y no de las competencias profesionales. En cuanto a las remuneraciones (miles de pesos) son homogéneas, situándose entre los 251 y los 451. 
4. Educación: se presentan cuatro casos de profesores de educación general básica, un profesor en educación física, una educadora diferencial, dos educadoras de párvulos de universidad privada con apoyo estatal y una educadora de párvulos de universidad privada.

La inserción laboral depende del mercado de trabajo, contactos sociales y capital social individual. Para el caso de los profesores básicos su inserción es rápida, trabajan en escuelas municipales en sus localidades de origen y llegan por contactos políticos. Existe escasa movilidad ocupacional; sin embargo, su situación contractual es a contrata $^{11}$, su renovación depende del alcalde.

Las educadoras de párvulos y educadora diferencial consideran que el mercado laboral está saturado. Para conseguir un empleo no basta con las competencias adquiridas en la universidad, se requiere de contactos sociales y capital social individual. Se sienten decepcionadas por los bajos sueldos, tres casos se perfeccionan con la finalidad de explorar nuevas oportunidades laborales; sin embargo, ninguna de ellas mejora sus ingresos. Sólo dos mantienen su trabajo y una lo pierde. Las remuneraciones (miles de pesos) son homogéneas situándose en 251-451.

5. Salud: conformada por dos enfermeras de universidad privada con apoyo estatal, dos odontólogos y una tecnóloga médica de universidad estatal.

La inserción laboral para este grupo es por demanda. Los empleos se obtienen por contactos en los centros de práctica y concurso público o privado, presentando una baja movilidad laboral.

Enfermeras y odontólogos trabajan en el sector público. Consideran que en los últimos años han mejorado las remuneraciones de los trabajadores, hay beneficios en perfeccionamiento, bonificación por trabajar con pacientes críticos, entre otros.

11 Son contratos de trabajo renovables cada año. 
Los odontólogos trabajan en consultorios municipales. Señalan que su situación contractual es inestable, ya que cada año deben esperar su recontratación, la que depende del municipio. Implementar una clínica propia implica costos elevados, por esta razón trabajan algunas horas a porcentaje en el sector privado. Sus remuneraciones (miles de pesos) son homogéneas, situándose entre los 1.000-1.500.

Ambas enfermeras trabajan en el sector público -en el hospital regional de Rancagua y en el de Talca. Su situación contractual es de planta y las remuneraciones (miles de pesos) se ubican en el tramo 651-850.

La tecnóloga médica, debido a la escasa oferta laboral y a las bajas remuneraciones en la región, migra a Santiago, donde se desempeña en una clínica privada y realiza docencia en una universidad privada. En cuanto a su remuneración (miles de pesos) se ubica en el tramo de 851-1.000.

Los profesionales de la salud en su conjunto critican las largas jornadas laborales que desempeñan, señalando un costo familiar importante. Debido a las exigencias del medio, algunos de ellos han estudiado o están cursando un magíster como una forma de mejorar o mantener sus ingresos.

6. Comunicaciones: compuesta por dos relacionadores públicos ${ }^{12}$ de universidad privada. Presentan dificultades de inserción laboral debido al desconocimiento que tienen los empleadores del quehacer profesional y la falta de especialización que permita establecer diferencias con otras áreas, como periodismo, trabajo social, entre otras.

El tiempo para encontrar trabajo es de un año y se hace a través de contactos sociales y de méritos. La movilidad laboral es baja, pero en ambos casos se experimenta la falta de proyección ocupacional, lo que denominan "efecto techo". Por esta razón, uno de ellos ha incursionado en la creación de una empresa comunicacional, otro quisiera crear una empresa de eventos pero no tiene los medios económicos.

12 Cabe señalar que esta carrera se cerró el año 2004, con la última generación de titulados. 
Ambos trabajan en el sector privado. La mujer es ejecutiva de crédito automotriz en un banco; su remuneración (miles de pesos) está en el tramo de 251-451. El varón se desempeña como encargado zonal de una caja de compensación y su remuneración (miles de pesos) está en el tramo de 651-850.

\section{Movilidad social}

a) Significados de la movilidad social

El significado que atribuyen a la movilidad social se relaciona con las experiencias biográficas, marcadas por los cambios del mundo rural y sus consecuencias en la estructura de oportunidades educativas. La similitud sociocultural de los sujetos tiende a definir trayectorias y conjunto de experiencias afines que configuran una noción común (discursos) respecto a la movilidad.

Se comparte la noción de movilidad estructural. Se percibe que muchos miembros del mundo rural han cambiado en las últimas décadas de posición social, debido a las mejoras en calidad de vida, acceso a la vivienda, educación, servicios básicos, conectividad, consumo, crédito, por ejemplo.

Tres son los significados que se atribuyen a la educación universitaria como mecanismo de movilidad social individual.

1) Como cambio de una clase social a otra: cambio de posición social con relación a los progenitores, que ocurre cuando se accede a mejores niveles educativos, ocupacionales y de ingresos.

2) Como mejora en las condiciones de vida: se percibe como mejoría en las condiciones materiales, acceso al consumo, servicios, protección social con relación a los progenitores.

3) Como aumento del prestigio social: se entiende como el reconocimiento y valoración social por parte de la comunidad de origen al portador de credenciales universitarias.

b) Trayectorias de movilidad:

Según las experiencias biográficas, los sujetos muestran tres direcciones respecto de su clase de origen: 
1. Movilidad ascendente ${ }^{13}$ : sujetos con familias de origen pobre ${ }^{14}$. Para estos casos, la educación universitaria funciona como mecanismo de movilidad social. Objetivamente, a través de sus profesiones logran mejores ocupaciones e ingresos. Consideran relevante en su proceso de movilidad el prestigio social alcanzado en sus comunidades de origen. La alta valoración y el reconocimiento social que entregan sus credenciales los sitúa en un estatus más alto que el de sus padres.

Cinco casos de origen pobre declaran cambiar a clase mediamedia. Explican su posición por el estatus asociado al prestigio de su profesión y los ingresos que permiten el acceso a bienes tecnológicos, el crédito y, en algunos casos, la casa propia y el automóvil.

Se observa un mejoramiento objetivo y subjetivo en relación con sus familias de origen. Este grupo está compuesto por tres profesores de educación general básica, una trabajadora social y un contador auditor.

Un caso de origen pobre declara cambiar a clase media baja ${ }^{15}$. Es una ingeniera comercial que no ha tenido oportunidades de trabajar en lo que estudió y desempeña labores docentes en un colegio. Aún así considera que portar un título universitario le asigna un estatus social mayor en relación con sus pares de origen.

Se presentan siete casos, que se mueven de clase media baja a clase media-media ${ }^{16}$. Explican este trayecto por el aumento de ingresos, niveles de vida, contactos sociales y prestigio. Se ubican en estas posiciones dos trabajadoras sociales, un ingeniero comercial, una relacionadora pública, una educadora de párvulos y una agrónoma.

En cuanto a la movilidad de clase media-media a clase mediamejor $^{17}$, diez casos manifiestan su nueva posición por ingresos altos

13 Movilidad ascendente se refiere a individuos que mejoran su posición en la estructura social. 14 Pobres: individuos sin acceso a bienes y servicios, con necesidades básicas insatisfechas.

15 Clase media baja: individuos con escaso acceso a bienes y servicios, con espacios restringidos de consumo, pero con necesidades básicas satisfechas.

16 Clase media-media: individuos con acceso a bienes y servicios, con apertura al consumo.

17 Clase media-mejor: individuos con acceso a bienes y servicios sin restricción. 
y consumo sin restricciones. Sus ocupaciones los relacionan con una elite que influye sus prácticas sociales (habitus), situándolos en una posición privilegiada respecto de sus orígenes.

Se encuentran en esta situación dos agrónomos-enólogos que trabajan en producción de vinos; un agrónomo que trabaja para una empresa transnacional; dos enfermeras en unidades de pacientes críticos; una tecnóloga médica en unidad de banco de sangre en clínica privada; un relacionador público encargado comunicacional regional de una caja de compensación, y una trabajadora social encargada de participación ciudadana en proyecto bicentenario del Ministerio de Obras Públicas.

El caso de los odontólogos es particular. Reciben las mayores remuneraciones, sin embargo, consideran falta de roce social, develan que sus ocupaciones -consultorios de las localidades de origenclausuran contactos con otras experiencias sociales y culturales.

2. Movilidad horizontal ${ }^{18}$ : tres casos se mantienen en clase media-media, dos consideran que el acceso a la universidad permitió reproducir la posición social de la familia de origen. Uno de ellos -educadora diferencial- explica su situación por la oferta de sueldos similar a la de su familia de origen. El segundo se trata de una trabajadora social que busca construir un proyecto de vida relacionado con el trabajo agrícola y los modos de vida del mundo rural. Sus ingresos los destina a inversión en tierra e insumos, por este motivo no aumenta su calidad de vida ni bienes en relación con sus padres.

Un último caso es un trabajador social que ha trabajado en cargos públicos bien remunerados, con poder y prestigio -cargo político-, que al momento de la entrevista está cesante. El sujeto se percibe en la misma posición social de los padres, pero devela la posibilidad de empeoramiento.

3. Movilidad descendente ${ }^{19}$ : seis entrevistados perciben deterioro social y/o económico con relación a sus padres. Cuatro declaran

18 Movilidad horizontal: cuando el sujeto mantiene la posición social de origen.

19 Movilidad descendente: cuando el sujeto percibe deterioro social y económico con relación a sus padres. 
bajar de clase media-media a media baja muestran una situación de empeoramiento, sus ingresos son bajos, tienen restricciones en el consumo, cesantía, en algunos casos presentan endeudamiento y falta de contactos sociales. La elección de carrera no facilitó el acceso a mejores posiciones por la sobreoferta de profesionales, bajas remuneraciones e inestabilidad laboral.

Un caso de origen de clase media, cree que su posición mejorará. Es un profesor de educación física que acaba de encontrar trabajo en su profesión. Por otra parte, una educadora de párvulos cesante y un profesor que no desempeña su profesión piensan que su situación (desesperanza) se mantendrá.

Un ingeniero agrónomo de clase media, percibe que su posición social es inferior debido a que su familia de origen aumentó su calidad de vida e ingresos y el padre tiene una red de contactos sociales prestigiosa. Objetivamente, sus ingresos no coinciden con su percepción, pues se ubica en el grupo con mejor remuneración.

Por último, una educadora de párvulos de clase media-baja siente estar en desventaja, ya que el cese de la labor de crianza de sus padres disminuyó sus gastos y se movilizaron de posición social, aumentando su calidad de vida y acceso a bienes y servicios. Otra razón de su descenso es la cesantía de su marido -psicólogo-, por lo que ha debido ser jefa de hogar. Aun cuando se encuentra en desventaja, considera que tiene una calidad de vida aceptable y cree que al emplearse el marido la situación mejorará.

c) Elementos que gatillan la movilidad social:

La educación es considerada uno de los principales mecanismos de movilidad social. Reconocen que para la población en situación de pobreza la educación universitaria siempre implicará mejoras en su posición social. Para la clase media es un mecanismo mantenedor, sólo permite aumentar el bienestar y consumo.

El solo hecho de acceder a las credenciales universitarias no asegura el éxito, sobre todo en contextos de creciente oferta profesional y competencia por los puestos de trabajo. Resaltan dos dispositivos 
que deben acompañar al sujeto: el capital social individual que facilite desarrollar las mismas actividades u otras con mayores beneficios, y contactos prestigiosos que permitan al sujeto integrarse a mejores posiciones. Otro dispositivo relevante es la apropiación de estilos de vida de la elite, por lo que si se quiere estar en una mejor posición social se deben aprender estos habitus.

Finalmente, identifican al capital económico como el único dispositivo que permite formar parte de la clase alta, a la que no se accede por logros académicos ni prestigiosas ocupaciones, sino por la acumulación de riquezas.

\section{Visión del mundo rural}

El periodo del 2000 marca el inicio de una nueva forma de percibir lo rural, en la cual no está separado de lo urbano, aunque existen particularidades que guardan relación con un sustrato valórico e identitario, vinculado con modos de ser y de relacionarse con el mundo.

De los cambios vivenciados, el más valorado es la conectividad vial. La ruptura del aislamiento significa que lo rural y lo urbano corren en dos líneas conectadas. Esta situación se refleja en que varios entrevistados trabajan en la ciudad pero viven en sus localidades de origen, o viven en la ciudad y prestan servicios al mundo rural.

Se percibe un aumento en la cobertura de los subsidios para la vivienda. Muchas familias tienen acceso a la construcción o mejoras de sus casas. En el ámbito del consumo, consideran que se ha masificado el acceso a artefactos tecnológicos y vestuario.

Destacan que en esta década el acceso a la educación universitaria se ha masificado debido a una mayor oferta en el territorio, acceso a créditos y otros beneficios que permiten su financiamiento. Señalan que hoy día existen mayores oportunidades educativas que en el periodo que ellos ingresaron.

El vínculo que establecen con la ruralidad se da de tres formas: aquellos que se identifican con un sustrato rural; aquellos que a través 
de la entrevista hacen una reflexión de sus vidas y reconocen su relación con el mundo rural, y aquellos que se consideran urbanos, marcados por los estereotipos sociales dominantes que definen lo rural como atrasado, inculto, tradicional, entre otros.

En esta última forma encontramos relatos que reflejan cómo el sujeto busca borrar los anclajes campesinos para integrarse a la sociedad urbana. El medio que utilizan es el consumo, imitando estilos de vida propios de la ciudad, pero continúan conectados con sus familias de origen, con las que se visitan periódicamente e incluso viven.

Los relatos develan un sentido de pertenencia con el territorio. Los vínculos con sus familias y los modos de vida de la provincia los hacen permanecer en las localidades. Cinco casos migran de la región en busca de mejores posibilidades laborales y sólo uno manifiesta que no volvería a su lugar de origen.

Existe la percepción de que la región ofrece escasas oportunidades de desarrollo. Las razones se asocian a una política incapaz de generar un proyecto que permita mejoras laborales y de ingreso.

\section{Conclusiones}

A pesar de la variedad de experiencias que muestran los relatos biográficos, es posible rescatar sentidos compartidos -consensosque permiten interpretar la relación entre educación universitaria y movilidad social.

En primer lugar, el estudio mostró que el 53\% de los entrevistados consideran a sus familias de origen en clase media. En estas existe la idea de que la educación es un mecanismo para asegurar la reproducción de la posición social de origen y mejorar el nivel de vida de los hijos, cuestión que coincide con la $3^{\text {a }}$ hipótesis de trabajo.

El estudio mostró que, para los sujetos entrevistados, la noción de movilidad transita desde el cambio de posición social de origen a la mejoría en las condiciones de vida y el prestigio social alcanzado. 
La educación universitaria opera como mecanismo de movilidad social sólo en la clase baja -pobres- y en la clase media baja, lo que confirmaría la $1^{\text {a }}$ hipótesis de trabajo.

"La universidad permitió el cambio de clase social (...) si uno lo piensa ahora sí, porque de vivir en una mediagua con pozo negro a vivir en una casa con baño cambia la cosa. La universidad permite un cambio de vida, es muy distinto, es un cambio ciento por ciento" (Rosa).

En los casos con familias de origen de clase media, la educación universitaria eleva el nivel de vida y bienestar. Para algunos se expresa en un cambio de estrato dentro de la misma clase. Un elemento que afecta la movilidad, a juicio de los entrevistados, es el aumento de profesionales en el mercado de trabajo; por esta razón, las credenciales no aseguran el éxito y se requieren otros elementos, como contactos sociales y capital social individual. De este modo, para los sectores medios la educación por sí sola pierde la función de facilitar el ascenso social.

"La universidad, por sí misma, no me habría permitido lograr las cosas que he logrado. La universidad enseña, da el pie, pero uno tiene que tener los contactos. En otras carreras a lo mejor no es necesario el tema de las redes, por ejemplo en medicina, me imagino que uno entra a trabajar, más que nada por los antecedentes académicos. Pero en esta carrera no, te piden al principio los antecedentes académicos, pero también preguntan, usted a qué partido pertenece, de parte de quién viene, es familiar de..." (Pamela).

Los entrevistados, en general, consideran pertenecer a la clase media. Explican esta posición social por el aumento de la calidad de vida, acceso al consumo y prestigio social, el que se logra a través de la educación. Sin embargo, llama la atención que no existe un correlato entre la percepción positiva de su condición de vida y los bajos ingresos que reciben.

Pareciera que los sujetos adoptan un concepto de la clase media que los diferencia de los ricos y de los pobres, ubicándolos 
en el centro de la estructura social. El punto medio implica tomar distancia de la precariedad de los sectores pobres, aun cuando en algunos relatos se devela un límite difuso con posible descolgamiento, por la falta de seguridad en sus posiciones debido a desprotección social e inestabilidad de los empleos.

Por otra parte, resulta interesante la visión que tienen del acceso a la clase alta. Interpretan que es un grupo social cerrado, al que no se puede ingresar por títulos académicos. La entrada se logra por capital económico definido como posesión de riquezas y portar ciertos estilos de vida de la elite.

"sabes que cambiar de clase social, como que eres pobre a ser rico no, a clase media por ser universitario sí. Pero definitivamente ayuda a mantenerte en tu clase, si eres clase media, pero así como cambiar de clase media a alta, creo que con medicina, ingeniería civil, odontología, por ahí no más, porque si ves los sueldos de profesionales, no es tanto tampoco, no pasan de clase media. Si tú eres de clase baja, te puede servir, vas a llegar a clase media, pero si eres de clase media, es como eso no más, con la universidad no vas a pasar a clase alta, eso se logra creo yo, al tener algún negocio, ganar plata por otra cosa, pero por la universidad no creo, eso es una ilusión que no hay que tener, porque es falso, es absolutamente falso" (Lucía).

Existe una noción de movilidad estructural explicada por oleadas modernizadoras que en los últimos 20 años han cambiado al mundo rural. Se percibe que la población, en general, mejora los niveles de vida. En este contexto, lo rural se redefine como una zona de actividades diversas -agrícolas, comerciales, servicios, con pequeñas y medianas empresas- y en las que conviven ciudades, pueblos, aldeas, villorrios. La vieja división rural y urbana parece no operar. Los relatos manifiestan una clara interdependencia económica, comercial y de servicios entre los territorios, lo que Edelmira Pérez acuña como "nueva ruralidad".

"San Clemente era pobre, tenía sectores pobres, de hecho las poblaciones antes eran muy pobres, ahora han salido adelante a flote. Antes acá eran tomas, medias aguas, 
los sitios divididos con rejas eran poblaciones todas de madera, o sea, hay un cambio hoy día. San Clemente no es igual, ha cambiado, los mismos chicos han cambiado; por ejemplo, ahora se ven muchos niños, muchos jóvenes que están en la universidad, antes cuándo, jeso era como inalcanzable en los tiempos que yo era chica!" (Eugenia).

En relación con la estructura de oportunidades educativas, los resultados muestran que son limitadas. La etapa de enseñanza básica de los entrevistados se restringe en general a establecimientos municipales rurales de baja calidad. La enseñanza media transita entre establecimientos municipales de baja calidad y los de excelencia académica ubicados en centros urbanos al cual asisten los alumnos aventajados.

En general, los entrevistados critican el sistema escolar por la inequidad en la formación. Una vez que ingresan a la universidad deben esforzarse mucho para nivelar su desempeño respecto de sus pares. Las escasas oportunidades de formación que pudieron afectar los rendimientos de PAA están mediadas por los determinantes sociales que inciden en la elección de carrera. El perfil homogéneo de los entrevistados converge en áreas de estudio conocidas y familiares, como Pedagogía Básica, Agronomía, Educación Parvularia y Trabajo Social, que no siempre cumplen las expectativas ocupacionales y de remuneración.

"Mi familia es la más feliz del mundo, porque tengo un título, saqué mi carrera en los años que correspondía y todo el cuento. En lo que respecta al campo laboral, digamos, al ver lo que es el salario, me deprimí. O sea, mi primer sueldo fue muy poco, era feliz porque no le había pedido un peso a nadie, pero después me empecé a dar cuenta de que con eso no podía vivir todo el resto de mi vida, con el sueldo que gana una educadora de párvulos, si tú quieres tener hijos, tener una familia, no vas a solventar todos los gastos" (Constanza).

En este sentido, la $2^{a}$ hipótesis señalaba que la segmentación del mercado universitario (Brunner) estaría afectando el acceso a puestos 
de trabajo y generando un proceso clasista de selección al interior del sistema educacional. Para los casos en estudio sería explicativo en parte, dado que los resultados muestran un entramado de factores bastante complejos. Para estos alumnos, egresar de universidades tradicionales o privadas no estaría siendo determinante a la hora de encontrar trabajo: la selección se produce por la elección de carrera, los contactos y el capital social individual.

De este modo, se observa que las carreras del área de salud son las más exitosas en términos de demanda del mercado y remuneraciones. Para aquellos que eligieron carreras clásicas y que logran insertarse en ocupaciones con buenas remuneraciones, el factor decisivo es el capital social individual -actitud emprendedora- y los contactos sociales prestigiosos.

Si se considera que la generación en estudio es la primera oleada del proceso de masificación universitario en la región del Maule, preocupan a los entrevistados las oportunidades efectivas de la estructura ocupacional para absorber la oferta de profesionales. Se apela al Estado para regular las carreras con un exceso de profesionales y una escasa demanda (ciegas). Por otra parte, se propone la búsqueda de salidas laterales que no impliquen necesariamente el acceso a la educación universitaria.

"No había trabajo, no había ni una cosa, leía el diario, tiraba currículo para todos lados, no... cero, cero, ningún... me desesperé, empecé a pensar en cosas chicas, no quedaba otra... tenía un amiga en el Líder (supermercado), fui a conversar con ella y me dijo ¡lo único que te puedo ofrecer es cajero! y ahí fui, estuve de cajero como ocho meses en el Líder, cuando dije: estudié, cinco años, seis años de estudio y estoy aquí... "(Fernando).

Debido al perfil de los entrevistados -bajo capital social e individual y escasos contactos-, es imprescindible considerar el desarrollo de habilidades sociales y la generación de redes en los procesos formativos de las universidades. El proceso de masificación del sistema universitario plantea nuevos desafíos educativos, entre ellos, que la adquisición de conocimientos debe ir acompañada del 
cultivo de espacios sociales que permitan su activación. En contextos de crecientes niveles de educación, la diferencia estará en la actitud que tome el sujeto frente al trabajo, su capacidad de liderazgo, responsabilidad y disciplina.

"Uno tiene que sacar esa timidez..., uno es como pajarito... el roce social le va dando a uno... Oiga, yo estuve en el Hotel Marriot, en un seminario, fui por intermedio de un profesor de la universidad, ahí me di la mano con Vittorio Corbo, con don Roberto Fantuzzi, me tomé un café... Quién puede decir que estuvo con Corvo... que fue presidente del Banco Central. Estuve con ministros, con Viera Gallo, con el de Relaciones Exteriores, el rector de mi universidad, antes de la actual ministra de Agricultura, don Álvaro Rojas Marín, entonces esas personas también fueron provechosas en la universidad... porque el roce, las redes pueden ser más importantes que la misma universidad... porque con el título en la mano... uno lo va a presentar en cualquier parte y te dicen quién eres tú, y..." (Camilo).

Con relación al mundo del trabajo, se concluye que el acceso depende mayoritariamente de los contactos sociales (cadena de favores). Existe la percepción de que en Chile el "pituto" es una institución más importante que las credenciales académicas para encontrar trabajo.

"El principal problema es que en esta zona la ciudad es muy chica y hay poco trabajo. Y todos los trabajos que se pueden conseguir son con "pituto". De hecho, así entré al liceo, a trabajar, por un "pituto", un conocido me ayudó a entrar. El problema es que por el hecho de vivir en el campo, soy de una familia humilde, no tengo grandes contactos, como para que me contacten, para entrar a trabajar a un banco, por ejemplo". (Paulina).

Por otra parte se considera que las condiciones laborales son en general inestables. Destaca especialmente el sector municipal por la excesiva politización de la que dependen las contrataciones cada año. Por otro lado, se considera al Estado un mal empleador, que contrata servicios a honorarios, sin protección social para el trabajador. 
Los entrevistados con buenas remuneraciones critican sus extensas jornadas o el desempeño en varios trabajos. Los costos siempre se asocian a la falta de tiempo para la familia o la postergación de la maternidad. Piensan que el exceso de trabajo es algo transitorio, mientras se logra generar un capital económico; sin embargo, en la reflexión dudan que esto sea real, develando resignación.

Destaca un grupo importante que ve la posibilidad de generar emprendimientos que permitan la independencia laboral. Llama la atención cómo se instala en el imaginario social la idea de ser empresario. En el fondo, visualizan que sus carreras tienen un techo y que la forma de proyectarse es a través de la utilización de capacidades adquiridas en la universidad.

"Siempre me dan ganas de meterme en una cuestión, de poder hacer un negocio, no sé, de crecer, de cualquier cosa, siempre he tenido la idea de independizarme. Obviamente, no le cuento a nadie, porque son ideas locas, de repente me dan ganas de vender el auto y comprarme una micro me pongo... y manejo... Pienso: a ver si pongo tal empresa, cómo empiezo... de cualquier cuestión, obviamente el capital, voy a ser yo no más, si tú vas a tener que hacer todo, secretaria, gerente, trabajador, empleado, todo junto. El tema es cómo empezar, dónde vas, a lo mejor hay instituciones del Estado que te podrían ayudar" (Fernando).

Los hallazgos muestran que la mayoría de los entrevistados continúan en sus territorios. Las razones expuestas son la presencia de un vínculo fuerte con sus familias de origen y la valorización del modo de vida rural. Estos resultados refutan la $4^{a}$ hipótesis que señalaba la desruralización, producto de los procesos de profesionalización y de una oferta laboral inadecuada que obliga a migrar.

Agradecimientos: al Consejo Superior de Educación, por generar espacios y condiciones que permitan la indagación y reflexión en temas que pueden aportar a mejorar los procesos de profesionalización, equidad y calidad de la formación universitaria. A E. Barozet por su orientación metodológica y teórica, como por su rigurosidad. Especialmente, a los entrevistados que compartieron sus vidas para que este estudio fuera posible. 


\section{Referencias bibliográficas}

Atria, Raúl (2004) Estructura ocupacional, estructuras y clases sociales. CEPAL, División de Desarrollo Social, Serie de Políticas Públicas No 96.

Boudon, Raymond (1983) Las desigualdades de oportunidades: la movilidad social en las sociedades industriales: Barcelona España: Ediciones Laia.

Bourdieu, Pierre y Passeron, Jean (1995) La Reproducción: elementos para una teoría del sistema de enseñanza. Barcelona España: Ediciones Fontamara.

Bourdieu, Pierre (1998) La Distinción. Buenos Aires, Argentina: Editorial Taurus.

Brunner, Joaquín (2006) Sistema privatizado y mercados universitarios: competencias reputacional, sus efectos. Sitio en Internet. Disponible en http://www.educarchile.cl/mt/jjbrunner/archives/2006/03/mercados

Canales, Manuel (2005) Chile Rural. Un desafío para el desarrollo humano. Santiago de Chile: Temas de desarrollo sustentable $N^{\circ} 12$. Programa de las Naciones Unidas para el Desarrollo (PNUD).

Canales, Manuel (2006) Metodologías de Investigación, Introducción a los oficios. Santiago de Chile: Editorial LOM, p. 32.

Glaser, Barney y Strauss, Anselmo (1967) The discovery of grounded Theory. Strategies for qualitative Research. Chicago: Algine Publishing Company.

Granovetter, Mark (1973) The strength of weak ties. American Journal of Sociology, 78(6), pp. 1360-1380.

León, Arturo y Martínez, Javier (2001) La estratificación social chilena hacia fines del siglo XX. CEPAL, División de Desarrollo Social, Serie de Políticas Públicas No 52.

Márquez, Francisca (2001) Trayectorias de vida y trabajo en sujetos pobres. Proposiciones, 32, Sur Profesionales, Santiago, Chile.

Méndez, María Luisa (2002) Experiencias y significados asociados a la idea de movilidad social en el relato de doce familias floridanas. Sitio en Internet, Disponible en http://socialesuchile.cl/publicaciones/mad/06/ paper07.pdf

Mideplan (2006) Encuesta de Caracterización Socioeconómica. Sitio en Internet. Disponible en http://www.mideplan.cl

Pérez, Edelmira (2005) Chile Rural, un desafío para el desarrollo humano. Temas de desarrollo sustentable $N^{0} 12$. PNUD, Santiago, Chile. 
Rodríguez, Gregori; Torres, Javier y García, Eduardo (1996) Metodología de la Investigación Cualitativa. Ediciones Aljibe.

Rodríguez, Roberto (1998) Educación Superior y desigualdad social. Sitio en Internet. Disponible en http://redalyc.uaemex.mx/redalyc/src/inicio/ ArtPdfRed.jsp?iCve $=14000508$

Torche, Florencia y Wormald, Guillermo (2004) Estratificación y movilidad social en Chile: entre la adscripción y el logro. CEPAL, División de Desarrollo Social, Serie de Políticas Públicas No 98.

Recibido : 28 de mayo de 2009

Aceptado: 5 de junio de 2009 